\title{
Clinical evaluation of drug-induced hepatitis
}

\author{
L. Martí, J. A. del Olmo, J. Tosca, E. Ornia, M. L. García-Torres, M. A. Serra, F. Rodríguez, P. Lluch, \\ A. Escudero and J. M. Rodrigo
}

Service of Hepatology. Hospital Clínico Universitario. Department of Medicine. Universidad de Valencia. Valencia, Spain

\begin{abstract}
Objective: to ascertain the epidemiological characteristics, clinical symptoms, and evolution of drug-induced hepatitis over the last 22 years.

Experimental design and subjects: an observational, retrospective study between 1982 and 1993, and prospective study between 1994 and 2003. All patients in our department diagnosed with having drug-induced hepatitis were studied analyzing epidemiological (age, sex, cases per year, hospitalization) and clinical features (previous liver disease, hepatic symptoms, laboratory results), and follow-up (complete recovery or chronicity).

Results: a total of 61 patients were diagnosed as having drug-induced hepatitis, 26 men and 35 women (57\%), mean age 52.4 years \pm 17 years, of which $72.2 \%$ were older than 40 years. A total of $43 \%$ were admitted to hospital. In $87 \%$ of cases, two or more drugs were involved, the most frequent being antituberculosis (19 cases), psychotropic (26 cases), and nonsteroidal anti-inflammatory drugs (45 cases). Evolution showed that $94 \%$ of patients recovered after the withdrawal of suspected causal drugs.

Conclusions: the incidence of drug-induced hepatitis is higher in patients over 40 years of age, it being more common in females. Non-steroidal anti-inflammatory, psychotropic, and anti-tuberculosis agents were the main drugs involved. Most patients made a complete recovery after withdrawal of the suspected causal drug.
\end{abstract}

Key words: Acute hepatitis. Drugs. Epidemiology. Evolution. Clinical characteristics.

\section{Recibido: 13-09-04.}

Aceptado: 23-11-04.

Correspondencia: Lidia Martí Romero. Servicio de Hepatología. Hospital Clínico Universitario. Avda. Vicente Blasco Ibáñez, 17. 46010 Valencia. Telf.: 653426 246. Fax: 963864 767. e-mail: liliger@ono.com
Martí L, del Olmo JA, Tosca J, Ornia E, García-Torres ML, Serra MA, Rodríguez F, Lluch $P$, Escudero A, Rodrigo JM. Clinical evaluation of drug-induced hepatitis. Rev Esp Enferm Dig 2005; 97: 258-265.

\section{INTRODUCTION}

Hepatic lesions as a consequence of adverse reactions to medication are a potential complication when prescribing any new drug, since the liver is the central metabolizing organ for foreign substances entering the body. Most drugs can be metabolized with no hepatic damage; however, new adverse reactions are occurring each year. Although most severe reactions have been described (1) and voluntary drug surveillance reports have been set up, these damaging reactions have not been evaluated in the general public, especially those which cause liver damage (2-4). Thus, we carried out a study of cases with drug-induced hepatitis diagnosed in our service over the past 22 years, and analyzed the epidemiological characteristics and drugs to which the development, clinical manifestation and evolution are attributed.

\section{PATIENTS AND METHODS}

The study includes all patients seen over a 22-year period (1982-2003) via a protocol established in 1994; cases prior to this date make up a retrospective study, whilst those presenting after 1994 are prospectively included. Cases were gathered following a revision of epicrisis in inpatients and in those diagnosed at the outpatient clinics. Parameters used to collect cases are shown in table I, and were obtained from a detailed revision of clinical histories. In all cases epidemiological and clinical data were collected, although the evolution process could not be studied in 4 patients. 
In agreement with the International Consensus Meeting recommendations, acute hepatic damage was defined as an increase in serum alanine-aminotransferase (ALT) levels or conjugated bilirubin above or equal to twice the normal upper limit, or a combination of increased aspartate-aminotrasferase (AST) and total bilirubin provided one of these values was more than twice the normal upper limit. Isolated increases in gamma-glutamyl transpeptidase (GGT) were not included in this study.

Diagnosis of drug-induced liver disease included the exclusion of lesions due to virus (A, B, delta, C in cases later than 1990, and nonA-nonB prior to this date, mononucleosis), autoimmune or metabolic disorders (iron and copper alterations and alpha-1 antitrypsin deficiency). Also excluded from the study were patients younger than 15 years and those with decompensated congestive heart failure, sepsis, regular alcohol intake of over $60 \mathrm{~g}$ per day, and conditions resulting in bile duct changes. Medicinal herb-induced hepatic changes were also excluded from the study.

Parameters obtained were introduced into an SPSS Windows database, and an ANOVA F was used for the comparison of quantitative variables.

\section{RESULTS}

For a 22-year follow-up period -from 1982 to 2003 sixty-one patients with a diagnosis of drug-induced hepatitis were seen. They had a mean age of $52.4 \pm 17$ years, with 26 being males $(54.8 \pm 15.4)$ and 35 females $(51.6 \pm 18.3)$. No difference regarding age was found in either group $(\mathrm{F}=0.18, \mathrm{p}=0.669)$. Most patients $(72.2 \%)$ were over 40 at the start of the study. The number of patients per year is shown in figure 1. Clinical findings and laboratory changes are shown in tables II and III, where the presence of jaundice, asthenia, and choluria was outstanding in half the cases. A high number of eosinophils was only detected in $8(13 \%)$ patients. Eleven cases (18\%) showed no clinical symptoms, and a diagnosis was reached following laboratory changes discovered during follow-up for the disorder that had warranted the prescription of drugs.

Drugs that may potentially produce acute hepatitis in patients can be found in table IV. Among 61 cases studied, only 8 patients were taking one drug; in 32 cases 2 or 3 drugs were being administered, and 21 patients were taking more than 3 drugs. The most frequent group of drugs responsible for hepatotoxicity was found to be nonsteroidal anti-inflammatory agents $(24.7 \%)$, antibiotics $(18.1 \%)$, neuroleptics $(14.3 \%)$, and agents used to treat the cardiovascular $(10.4 \%)$ and endocrine diseases $(8.8 \%)$.

The evolution of 57 of the 61 cases studied was followed; 8 of them had a past history of chronic hepatic disease of diverse etiology: 4 due to hepatitis C, 3 because of chronic alcoholism, and 1 with hepatitis B. Of
Table I. Parameters included in the protocol for druginduced hepatitis

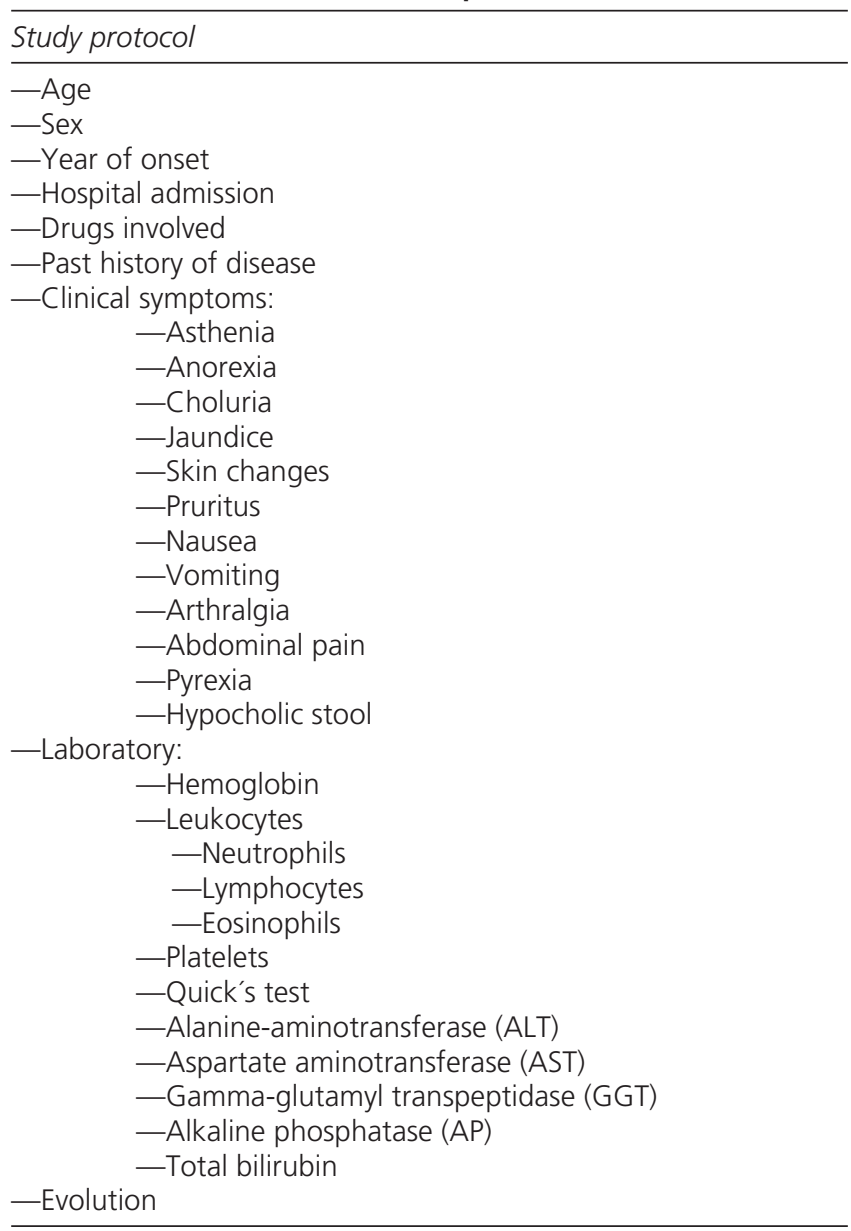

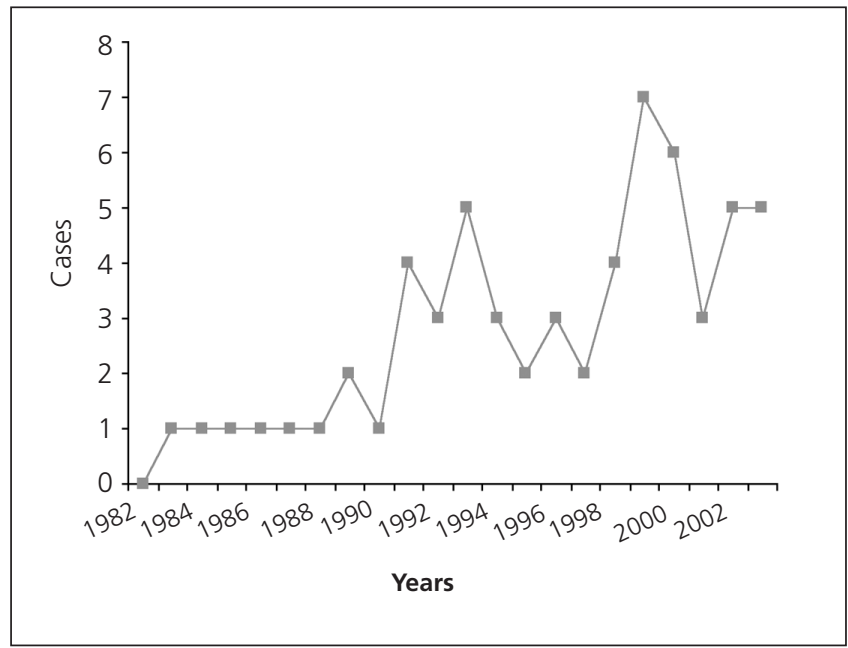

Fig. 1.- Number of cases of drug-induced hepatitis per year (19822003).

Número de casos por año de hepatitis por fármacos (1982-2003). 
Table II. Epidemiological and clinical characteristics of 61 patients with drug-induced hepatitis

\begin{tabular}{ll}
\hline Data & No. of cases (\%) \\
\hline Sex & \\
Males & $26(42.6)$ \\
Females & $35(57.4)$ \\
Age (mean \pm SD) & $52.4 \pm 17.5$ \\
Males & $53.6 \pm 16.6$ \\
Females & $51.6 \pm 18.3$ \\
Age groups (in years) & \\
$\quad$ 30 & $7(11.5)$ \\
$31-40$ & $10(16.5)$ \\
$41-50$ & $13(21)$ \\
$51-60$ & $18(29.5)$ \\
$\quad>60$ & $13(21)$ \\
& \\
Hospital admission & $26(42.6)$ \\
Clinical symptoms: & $30(49)$ \\
Asthenia & $16(26)$ \\
Anorexia & $28(46)$ \\
Jaundice & $28(46)$ \\
Choluria & $2(3)$ \\
Skin changes & $10(16)$ \\
Pruritus & $8(13)$ \\
Nausea and/or vomiting & $7(11)$ \\
Arthralgia & $4(6)$ \\
Abdominal pain & $3(5)$ \\
Pyrexia & $14(23)$ \\
Hypocholic stool & $11(18)$ \\
Asymptomatic &
\end{tabular}

Table III. Analytical changes seen in drug-induced hepatitis

\begin{tabular}{|c|c|c|c|}
\hline Laboratory data & No. of cases & Mean $\pm S D$ & $\begin{array}{l}\text { No. }(\%) \text { of } \\
\text { altered cases }\end{array}$ \\
\hline Hemoglobin & 61 & $13.6 \pm 1.6$ & $3(4.9 \%)$ \\
\hline Leukocytes & 61 & $6.968 \pm 2.662$ & $\begin{array}{l}\text { Leukopenia } 14(23 \%) \\
\text { Leukocytosis } 12(19.7 \%)\end{array}$ \\
\hline Platelets & 61 & $267,414 \pm 101,122$ & $6(9.8 \%)$ \\
\hline Quick's test & 57 & $85.3 \pm 16.5$ & $4(7 \%)$ \\
\hline Neutrophils (total) & 61 & $4422 \pm 1958$ & $\begin{array}{l}\text { Neutropenia } 12 \text { (19.7\%) } \\
\text { Neutrophilia } 5(8.2 \%)\end{array}$ \\
\hline Lymphocytes (total) & 61 & $1829 \pm 722$ & $\begin{array}{l}\text { Lymphopenia } 23(37.7 \%) \\
\text { Lymphocytosis } 0\end{array}$ \\
\hline Eosinophils (total) & 61 & $147 \pm 113$ & $\begin{array}{l}\text { Eosinopenia } 0 \\
\text { Eosinophilia 8/61 (13\%) }\end{array}$ \\
\hline AST $\left(^{*}\right)$ & 61 & $18.3 \pm 20.2$ & $61 / 61(100 \%)$ \\
\hline $\operatorname{ALT}(*)$ & 61 & $25.1 \pm 18.2$ & $61 / 61(100 \%)$ \\
\hline GGT $\left.{ }^{*}\right)$ & 59 & $8.1 \pm 6.2$ & $54 / 59(91.5 \%)$ \\
\hline Alkaline phosphatase $\left(^{*}\right)$ & 54 & $1.3 \pm 1.7$ & $46 / 54(85.2 \%)$ \\
\hline Total bilirubin $\left(^{*}\right)$ & 57 & $8.2 \pm 8.3$ & $43 / 57(75.4 \%)$ \\
\hline
\end{tabular}

${ }^{*}=$ Value expressed as number of times above normal values.

the remaining 49 patients, $46(94 \%)$ returned to normal clinical and laboratory patterns 12 months later. The remaining 3 continued to show high transaminase and/or alkaline phosphatase and/or GGT levels a year after illness onset. Histological studies carried out at 18, 20 and 24 months showed typical drug-induced toxic hepatopathy changes.
Table IV. Medication and drug groups found in 61 patients with drug-induced hepatitis (1982-2003)

\begin{tabular}{|c|c|c|c|}
\hline & $N^{0}$ & & $N^{0}$ \\
\hline Analgesics & 45 & Cardiovascular system & 19 \\
\hline Paracetamol & 9 & Antihypertensive drugs & 13 \\
\hline Ibuprofen & 15 & Enalapril & 4 \\
\hline Aceclofenac & 3 & Velsartan & 3 \\
\hline Aspirin & 10 & Atenolol & 3 \\
\hline Rofecoxib & 3 & Diltiazem & 1 \\
\hline Codeine & 4 & Quinalapril & 1 \\
\hline Paracodeine & 1 & Amiloride & 1 \\
\hline Antibiotics & 33 & Antiaggregants & 4 \\
\hline Clarithromycin & 6 & Trifusal & 3 \\
\hline Norfloxacin & 2 & Triclopidine & 1 \\
\hline Clavulanic acid & 6 & Vasodilators & 2 \\
\hline Antituberculosis & 19 & Dihydroergotoxin & 2 \\
\hline Streptomycin & 4 & Endocrine system & 16 \\
\hline Isoniazid & 6 & Hypolipemiant drugs & 8 \\
\hline Rifampicin & 7 & Prevastatin & 5 \\
\hline Pirazinamide & 2 & Genfibrozil & 3 \\
\hline Neuroleptics & 26 & Oral antidiabetes drugs & 6 \\
\hline Anxiolytics & 12 & Glibenclamide & 4 \\
\hline Diazepam & 7 & Glimpiride & 2 \\
\hline Alprazolam & 4 & Levothyroxine & 2 \\
\hline Bromazepam & 1 & Malignant disease & 10 \\
\hline Antidepressants & 7 & Tamoxifen & 5 \\
\hline Fluoxetine & 3 & Cyclophosphamide & 3 \\
\hline Paroxetine & 3 & Fludarabine & 2 \\
\hline Venlafaxine & 1 & Gastric secretion inhibitors & 10 \\
\hline Antiepileptics & 3 & Ranitidine & 6 \\
\hline Gabapentin & 2 & Omeprazole & 3 \\
\hline Carbamazepine & 1 & Rabeprazole & 1 \\
\hline Hypnotics & 1 & Musculoskeletal system & 7 \\
\hline Zolpirene & 1 & Tizanadine & 5 \\
\hline Anti-Parkinsonism & 1 & Alendronate & 2 \\
\hline Cabergoline & 1 & Other & 16 \\
\hline Antimigraine & 2 & Vitamins & 9 \\
\hline \multirow[t]{3}{*}{ Flunarizidine } & 2 & Tibolone & 1 \\
\hline & & Sex hormones & 5 \\
\hline & & Anetole y tritione & 1 \\
\hline
\end{tabular}

\section{DISCUSSION}

In our study, we carried out an epidemiological, clinical, and evolutive assessment of all drug-induced hepatitis cases diagnosed in our department between 1982 and 2003 following a protocol established in 1994.

Diagnosis required the presence of potentially hepatotoxic drugs as well as the absence of other etiologies such as those described in the material and methods section. Moreover, due to the fact that no test was available for the detection of virus $\mathrm{C}$ prior to 1990 , the following patients diagnosed as having hepatitis nonA-nonB hepatitis were excluded - patients who had had blood transfusions, patients addicted to intravenous drugs, and patients having undergone surgery. Also, the extended period of time for case gathering, and the methodology applied made us realize the potential existence of a biased selection of information on exposure to drugs, which may make data incomplete. 
On analyzing the frequency of drug-induced hepatitis diagnoses between 1982 and 2003, a clear increase was found during the last few years (Fig. 1). This could be influenced by diverse occurrences, such as an increased number of tests for detecting disease, increased drug-taking, or both. These facts are sustained because in our group $18 \%$ of patients were symptom-free, and the diagnosis was made using laboratory tests in patients who presented with other illnesses and who were taking potentially hepatotoxic drugs. Furthermore, we must point out that it is increasingly frequent to find recommendations about hepatotoxicity in oncology (5), pneumology with antituberculosis drugs $(6,7)$, endocrinology, and intestinal infections $(8,9)$, which might lead to consultation with an hepatologist. All this may also explain the differences found between our study and the study by Sgro et al. (10), as only symptomatic patients were included in the latter.

We must also point out that the absence of deaths in our series -as compared to those observed by other authors $(11,12)$ - is due to the fact that we only included patients seen in our department. In our hospital, patients with severe acute hepatic failure are directly cared for in the Intensive Care Unit or transferred to the referring hospital to be included in a liver transplantation program.

Patients with drug-induced hepatitis have several characteristics that distinguish them from other types of hepatitis. This includes the age factor, more frequent in females from 50 years upwards, and the taking of various types of medication, all of which is in line with that observed in other studies $(13,14)$. With respect to type of drug, we must point out that, currently, drugs considered in the 1960-1980 period to be frequently involved in hepatotoxicity, i.e., mainly chlorpromazine and halothane (15), non-steroidal anti-inflammatory analgesics, antibiotics, and others, are being now replaced, as can be seen in table IV.

In our study, we also highlight the small number of patients $(3 \%)$ who presented hypersensitivity skin reactions (cutaneous rash), with figures below the $20 \%$ shown by Lucena et al. (16). However, we did observe a high number of eosinophils in the peripheral blood in $13 \%$ of cases. Furthermore, regarding clinical findings, almost half of the patients showed jaundice and choluria, whilst 3 out of 4 patients had above-normal bilirubin levels. Laboratory tests showed that a majority of cases had high transaminase and bilirubin levels, and slightly raised alkaline phosphatase and GGT levels, similar to that observed by Contreras et al. (17).

A follow-up of patients allowed us to determine that a majority of them had cured within one year of diagnosis following the removal of the causal drug. Only 3 patients with drug-induced hepatitis and no previous history of hepatic disorders showed persistent signs of hepatic disease; while two of these patients had other disorders, obesity and diabetes, they had not shown any liver test abnormality prior to their drug-induced hepatitis, which, coupled to the al- terations shown in liver histology, led us to diagnose a chronic drug-induced hepatitis. The former three patients were taking more than 2 drugs, mainly combinations of analgesics and/or anxiolytics and/or antidepressants and/or oral antidiabetes medication and/or antibiotics.

In our study, we noted an increase in drug-induced hepatitis over the last few years in comparison with the 1980's. The disorder presents, above all, in patients over $40(72 \%)$ years, in those taking 2 or more drugs, and more frequently in women $(57 \%)$. We also noted that most patients return to normal clinical and laboratory health on withdrawal of the causal drug or drugs.

\section{REFERENCES}

1. Lee WM. Drug-Induced Hepatotoxicity. N Engl J Med 2003; 349: 474-85.

2. Bissell D, Gores GJ, Laskin DL, Hoofnagle JH. Drug-Induced liver injury: Mechanisms and test systems. Hepatology 2001; 33: 1009-13.

3. Teschke R. Drug-induced liver diseases. Z Gastroenterol 2002; 40: 305-26.

4. Sachs B, Haider S, Balaraman R, Shahab N, Perri MC. Hepatotoxicity of chemotherapy. Expert Opin Drug Saf 2002; 1: 339-53.

5. Center for Disease Control and Prevention (CDC). Update: adverse event data and revised American Thoracic Society/CDC recommendations against the use of rifampin and pyrazinamide for treatment of latent tuberculosis infection. United States 2003. Morb Mortal Wkly Rep 2003; 52: 735-9.

6. Chan KA, Truman A, Gurwitz JH, Hurley JS, Martinson B, Platt R, et al. A cohort study of the incidence of serious acute liver injury in diabetic patients treated with hypoblycemic agents. Arch Intern Med 2003; 24: 728-34.

7. Sgro C, Clinard F, Ouazir K, Chanay H, Allard C, Guilleminet C, et al. Incidence of drug-induced hepatic injuries: A French populationbased study. Hepatology 2002; 36 (2): 451-5.

8. Ibáñez L, Pérez E, Vidal X, Laporte JR. Prospective surveillance of acute serious liver disease unrelated to infectious, obstructive, or metabolic diseases: epidemiological and clinical features, and exposure to drugs. J Hepatol 2002; 37: 592-600.

9. Larrey D. Drug-induced liver diseases. J Hepatol 2000; 32 (Supl. 1): 77-88.

10. Schencker S, Martin RR, Hoyumpa M. Antecedent liver disease and drug toxicity. J Hepatol 1999; 31: 1098-105.

11. Tegeder I, Levy M, Muth-selbach U, Oelkers R, Neumann F, Dormann $\mathrm{H}$, et al. Retrospective analysis of the frequency and recognition of adverse drug reactions by means of automatically recorded laboratory signals. Br J Clin Pharmacol 1999; 47: 557-64.

12. Bagheri H, Michel F, Lapeyre-Mestre M, Lagier E, Cambus JP, Valdiguié $\mathrm{P}$, et al. Detection and incidence of drug-induced lever injuries in hospital: a prospective analysis from laboratory signals. $\mathrm{Br} \mathrm{J}$ Clin Pharmacol 2000; 50: 479-84.

13. Arndt, Hawkins D, Anderson JR, Breitfeld P, Womer R, Meyer W. Age is a risk factor for chemotherapy-induced hepatopathy with vincristine, dactinomycin and cyclophosphamide. J Clin Oncol 2004; 22: 1894-901.

14. Friis H, Andreasen PB. Drug-induced hepatic injury: an analysis of 1100 cases reported to the Danish Committee on Adverse Drug Reactions between 1978 and 1987. J Intern Med 1992; 232: 133-8.

15. Hartleb M, Biernat L, Kochel A. Drug-induced liver damage: a three year study of patients for une gastroenterological department. Med Sci Monit 2002; 8: CR292-6.

16. Lucena MI, Camargo R, Andrade RJ, Pérez-Sánchez CJ, Sánchez de la Cuesta F. Comparison of two clinical scales for causality assessment in hepatotoxicity. Hepatology 2001; 33: 123-30.

17. Contreras J, Poniachik J, Planzer M, Lazarte R, Smok G, Oksenberg $\mathrm{R}$, et al. Drug induced liver disease: clinical and pathological pattern in 33 cases. Rev Med Clin 2003; 131: 1128-34. 